\title{
Electrical stimulation for gastroesophageal reflux disease: current state of the art
}

This article was published in the following Dove Press journal:

Clinical and Experimental Gastroenterology

14 January 2016

Number of times this article has been viewed

\section{Sharon E Kim \\ Edy Soffer}

Department of Medicine, Keck School of Medicine, University of Southern California, Los Angeles, CA, USA
Correspondence: Edy Soffer Department of Medicine, Keck School of Medicine, University of Southern California, 1520 San Pablo Street, Los Angeles, CA 90033, USA

$\mathrm{Tel}+\mathrm{I} 3234428523$

Fax + I 3234425625

Email edy.soffer@med.usc.edu

\begin{abstract}
Patients with gastroesophageal reflux disease (GERD) who are not satisfied with acid suppression therapy can benefit primarily from fundoplication, a surgical intervention. Fundoplication has been the standard surgical procedure for GERD. It is effective but is associated with adverse effects, resulting in a declining number of interventions, creating a need for alternative interventions that are effective, yet have a better adverse effect profile. One such alternative involves the application of electrical stimulation to the lower esophageal sphincter. A number of animal studies showed that such stimulation can increase resting lower esophageal sphincter pressure. An acute human study confirmed this effect, and was followed by two open-label studies, with a follow-up of up to 3 years. Results thus far show that the therapy is associated with a significant improvement in symptoms, a significant reduction in esophageal acid exposure, and a very good safety profile. This review will describe the evolution of electrical stimulation therapy for GERD, as well as the safety and efficacy of this intervention.
\end{abstract}

Keywords: gastroesophageal reflux disease, lower esophageal sphincter, health-related quality of life

\section{Introduction}

Gastroesophageal reflux disease (GERD) is one of the most common gastrointestinal disorders. It affects up to $30 \%$ of the population in developed countries, but prevalence is increasing worldwide. ${ }^{1,2}$ GERD has a major negative impact on the quality of life of affected patients, ${ }^{3}$ and its economic burden to society is substantial. ${ }^{4}$

Nonpharmacological treatment measures involving lifestyle modifications, such as raising the head of the bed and avoidance of offending foods, are of limited help, ${ }^{5}$ and serve as an adjunct to acid suppression agents. Acid suppression therapy, provided primarily in the form of proton pump inhibitors (PPIs), remains the mainstay of medical therapy for GERD. The various PPI agents have revolutionized the treatment of GERD, given their remarkable efficacy and overall safety over the years. However, up to $40 \%$ of GERD patients complain of continued symptoms while receiving adequate acid suppression. ${ }^{6,7}$ The failure to fully control symptoms is due in part to the fact that acid suppression agents, no matter how potent they are, only reduce the acid content of the refluxed material, but not the reflux itself. ${ }^{7}$ This is supported by the importance of regurgitation as a factor contributing to the partial response to PPI therapy. ${ }^{8}$ Incomplete control of symptoms by acid suppression therapy is, in turn, one of the main reasons cited by patients who choose to undergo anti-reflux surgery., ${ }^{9,10}$ Furthermore, though PPIs have an overall good safety record, their use has been associated with various adverse effects (AEs) ${ }^{11}$ thus contributing to the quest for an alternative therapy. 
Fundoplication has been the standard anti-reflux surgery and the primary alternative for patients who are unsatisfied with pharmacological therapy because of poor symptom control or concerns about long-term cost and safety of PPIs. Fundoplication provides an effective control of GERD; however, it is associated with AEs, such as dysphagia, flatulence, and gas-bloat, and it requires a revision in a small percentage of subjects. ${ }^{12}$ Perhaps as a result, the number of fundoplications in the US is in decline. ${ }^{13}$ As a result, the unmet need of patients who are not satisfied with medical therapy and the traditional surgical approach has been driving a search for alternative treatment modalities, both endoscopic and surgical. A desirable alternative should be effective yet less disruptive, and with fewer AEs than a fundoplication. ${ }^{14}$ One such alternative is application of electrical stimulation to the lower esophageal sphincter (LES). This review will describe the evolution of this treatment modality, from studies in animal models through a proof of concept in humans and to currently ongoing studies in patients with GERD.

\section{Animal model LES electrical stimulation}

Studies in animal models used different techniques, pulse parameters, and protocols, but their results were comparable, showing that electrical stimulation of the LES can increase resting LES pressure. Early on, Ellis et al implanted two pairs of electrodes along the longitudinal axis of the LES in normal dogs and in animals in which the integrity of the gastroesophageal junction as a barrier to reflux was compromised by myotomy and the creation of a hiatal hernia. Following recovery, animals were studied under general anesthesia, using intraluminal pressure sensors. Experimenting with different pulse durations, frequencies, and voltages, the authors found that the optimal pulse parameters were a duration of $3 \mathrm{~ms}$ at 4 volts and at a frequency of $20 \mathrm{~Hz}$. Stimulation with these parameters induced a significant rise in pressure in both groups of animals. Pressure remained elevated for a number of hours during stimulation, and up to 5 hours when intermittent stimulation was applied through both pairs of electrodes. ${ }^{15}$ Using a different approach, Clarke et al applied an endoscopic technique for implantation of microstimulators in the submucosa of the gastroesophageal junction in three dogs. Studies were done with animals under anesthesia. Electrical stimulation delivered a succession of pulses of constant duration and frequency $(200 \mu$ s and $20 \mathrm{~Hz}$, respectively) while current was increased stepwise during each experiment. ${ }^{16}$ A significant increase in resting LES pressure was observed only when current exceeded $8 \mathrm{~mA} .^{16}$ In a chronic canine model, Sanmiguel et al implanted a pair of electrodes in the LES and studies were done in awake animals. Using a variety of pulse parameters, the authors found that stimulation with $375 \mathrm{~ms}$ pulses, of $5 \mathrm{~mA}$ at $6 \mathrm{cpm}$, resulted in a significant increase in resting LES pressure. The rise in LES pressure started after a delay of 5-10 minutes, and was sustained beyond the termination of stimulation. Importantly, swallow-induced LES relaxation and esophageal contractile activity were not affected. ${ }^{17}$

The results of these studies suggest that electrical stimulation of the LES and modulation of LES pressure may be used to treat GERD, and paved the way for subsequent application of such modality in humans.

\section{Acute human studies on electrical stimulation of the LES}

The successful results of LES electrical stimulation in animals led to two acute studies in humans, conducted as a proof of concept, in order to evaluate the effect of electrical stimulation on LES pressure in humans. The first study included ten patients with symptoms of GERD and documented abnormal esophageal acid exposure, who were scheduled to undergo an elective laparoscopic cholecystectomy. At the end of the procedure, two electrodes were implanted at each side of the LES and the lead was then exteriorized through the abdominal wall. Following recovery, the patients underwent a series of intermittent stimulation for 2 days, with various pulse parameters, each lasting 30 minutes, while esophageal motor function was assessed by esophageal manometry, using a water-perfused assembly. There was a consistent and significant increase in LES pressure with both high-frequency stimulation (pulse width of $200 \mu \mathrm{s}$, frequency of $20 \mathrm{~Hz}$, and current of 5-15 mA), and low-frequency stimulation (pulse width of $375 \mathrm{~ms}$, frequency of $6 \mathrm{cpm}$, and current of $5 \mathrm{~mA}$ ). The rise in pressure was observed after approximately 10 minutes following the start of stimulation, and was sustained beyond the end of stimulation (Figure 1). The enhanced pressure was sustained for at least 2 hours after cessation of stimulation in most patients, and for up to 4 hours in a few patients. There was no effect on LES relaxation in response to swallows, and none of the patients complained of dysphagia. ${ }^{18}$

In a second study, five patients with GERD symptoms and abnormal esophageal $\mathrm{pH}$ were fitted with a temporary pacemaker lead, placed endoscopically at the level of the LES. The lead was inserted by creating a $3 \mathrm{~cm}$ submucosal tunnel, secured to the esophagus by endoscopic clips, and was exteriorized transnasally. Electrical stimulation delivered short-duration pulses of $200 \mathrm{~ms}$, at a frequency of $20 \mathrm{~Hz}$, at intermediate duration of $3 \mathrm{~ms}$, each for 20 minutes. Current ranged between 2 and $15 \mathrm{~mA}$. Esophageal motor function was 


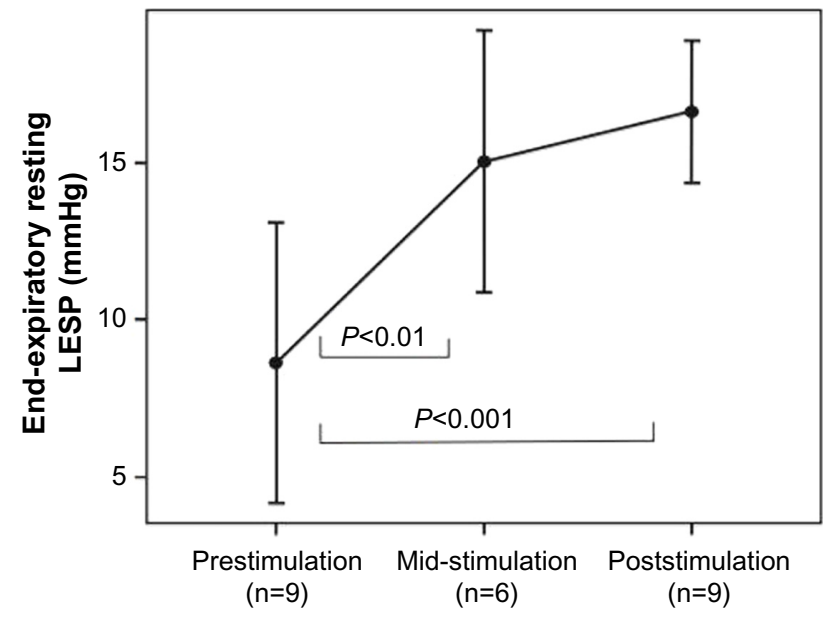

Figure I The effect on resting LESP of sustained stimulation with pulses of $200 \mu \mathrm{s}$, at a frequency of $20 \mathrm{~Hz}$, and with current ranging from 5 to $15 \mathrm{~mA}$.

Notes: LESP increased in all subjects $(n=9)$ at mid-stimulation ( 15 minutes) $(P<0.01$ compared to baseline), and increased further at the end of the 20-minute session $(P<0.00$ I compared to baseline). Data are presented as mean and $95 \%$ confidence interval. Reproduced from Rodríguez L, Rodríguez P, Neto MG, et al. Shortterm electrical stimulation of the lower esophageal sphincter increases sphincter pressure in patients with gastroesophageal reflux disease. Neurogastroenterol Motil. 2012;24:446-450. (C) 2012 Blackwell Publishing Ltd. ${ }^{18}$

Abbreviations: LES, lower esophageal sphincter; LESP, LES pressure.

assessed by high-resolution manometry. Comparable to the first study, both types of pulses $(20 \mathrm{~Hz}$, duration of $200 \mu \mathrm{s}$ or $3 \mathrm{~ms}$ ) resulted in consistent and significant increase in LES pressure, with delayed onset of 5-10 minutes that was sustained after the end of stimulation. Stimulation had no effect on swallow-induced LES relaxation, and none of the patients complained of dysphagia. ${ }^{19}$

The results of these studies prompted further assessment of this technology in GERD patients, by applying chronic stimulation using a permanently implanted system.

\section{Chronic human studies}

\section{Single-center study}

The consistent effect of LES stimulation on LES pressure, observed both in animal models and in acute human studies, was the impetus for the first chronic study in humans. The open-label trial was conducted in a single center in Santiago, Chile and enrolled patients with symptoms of GERD and documented excessive esophageal acid exposure by intraluminal esophageal $\mathrm{pH}$ monitoring. ${ }^{20}$ All patients were considering a surgical anti-reflux surgery, mostly because of incomplete response to treatment with PPIs, while a few were concerned about lifelong therapy with acid suppression agents. Safety was the primary endpoint, determined by the incidence of device- and procedure-related AEs. Efficacy was evaluated by the effect of stimulation on symptoms, assessed primarily by the reduction in the GERD Health-Related Quality of Life (GERD-HRQL) composite score as well as improvement in esophageal acid exposure. Patients were implanted with the EndoStim LES Stimulation System (Endostim BV, The Hague, the Netherlands) by conventional laparoscopy. Two electrodes were implanted in the muscular layer of the gastroesophageal junction, in the right anterior quadrant, and connected to a pulse generator located in a subcutaneous pocket in the left upper quadrant of the abdomen. The LES stimulation system delivered therapy with pulse width of $215 \mu$ s and nominal amplitude of $5 \mathrm{~mA}$ (range 3-8 mA) at a frequency of $20 \mathrm{~Hz}$ (Figure 2). Optimization of stimulation was attempted by variation of signal amplitude, frequency, and lead polarity. Up to 1230 -minute sessions were delivered per day at pre-meal and pre-reflux events based on patient symptoms and baseline 24-hour $\mathrm{pH}$ recordings. Of the 25 implanted patients, 23 were available for evaluation at 1 year. No serious implantation or stimulation-related AEs or sensations were reported. Specifically, new symptoms of dysphagia were not reported. Fifteen patients reported 44 AEs during the subsequent 12 months. Two serious AEs (SAEs), not related to the device or treatment, were reported. The first was an episode of chest discomfort with mild sinus tachycardia not temporally associated with LES stimulation sessions. The patient reported similar uninvestigated episodes prior to starting LES stimulation therapy. The episode resolved spontaneously. The patient was hospitalized and underwent an emergent cardiac catheterization that revealed normal coronary anatomy. A chest radiograph revealed stable lead position in the abdominal esophagus without any evidence of migration. The patient was diagnosed with esophageal spasm, was treated medically, and the symptom did not recur despite continued LES stimulation treatment. The second SAE involved a subject who was hospitalized for an elective thyroidectomy 3 months after the implant. The remaining 43 AEs were non-serious, mostly related to postoperative symptoms. No patient reported gastrointestinal side effects or new-onset dysphagia, bloating, inability to belch, or diarrhea associated with LES stimulation.

Median composite GERD-HRQL score and esophageal acid exposure were significantly improved at 12 months compared to baseline (Figure 3). All patients except for one were off PPI therapy. High-resolution manometry revealed no effect of LES stimulation on either esophageal body function or LES residual pressure in response to swallows, and there was no significant increase in LES resting pressure.

Twenty-one patients of the original cohort who completed 1-year follow-up were available for evaluation at the end of 2 years after implantation, and the results were recently published. ${ }^{21}$ At 2 years, GERD-HRQL scores were still significantly improved compared to baseline off and on PPI, with 


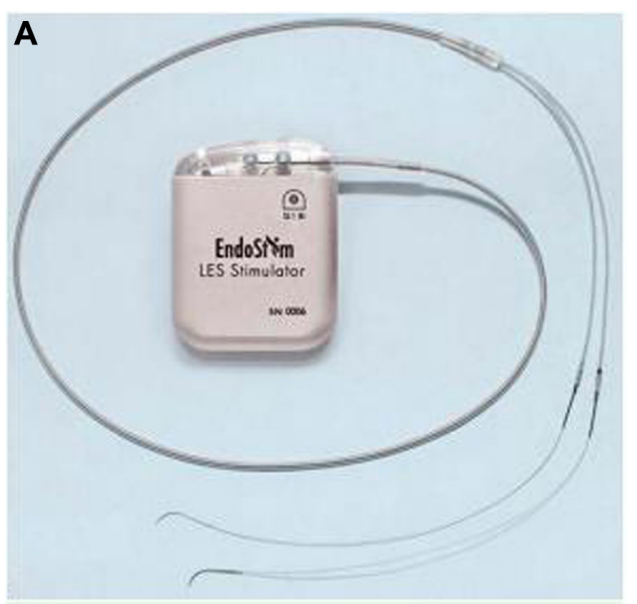

B

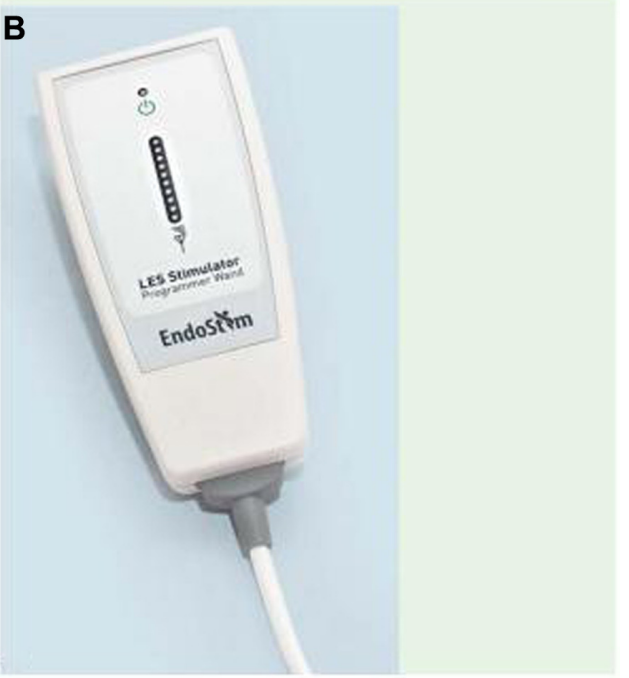

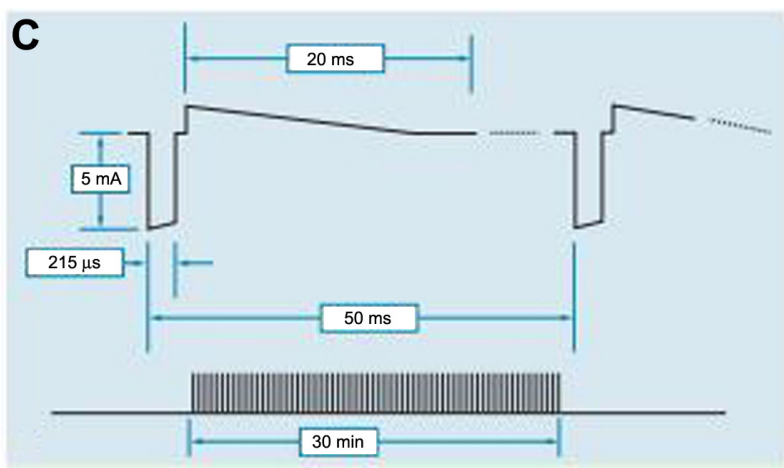

D

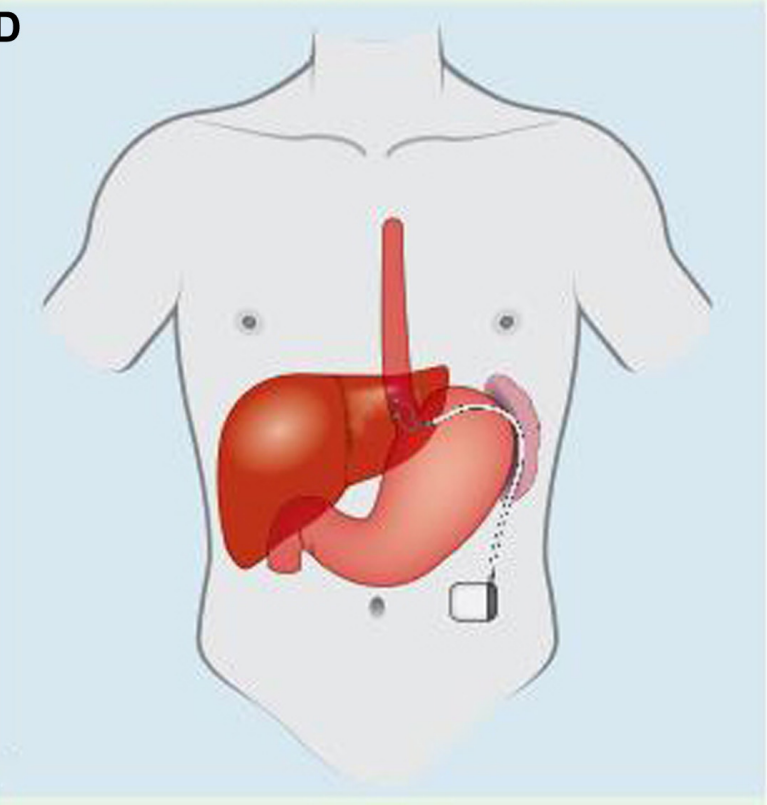

Figure 2 The EndoStim LES Stimulation System (EndoStim BV, The Hague, the Netherlands).

Notes: (A) The IPG (dimensions $65 \mathrm{~mm} \times 48 \mathrm{~mm} \times 12 \mathrm{~mm}$, weight $49 \mathrm{~g}$ ) is implanted in a subcutaneous pocket in the anterior abdomen. The bipolar electrodes are implanted in the LES and connected to the IPG. (B) The programmer is used to wirelessly program the IPG using radiofrequency signals. (C) LES stimulation pulse parameters. (D) Electrode position in the LES. Bipolar stitch electrodes are placed inline in the abdominal esophagus, I cm apart and away from the anterior vagus nerve. The lead is connected to the IPG that is implanted in the subcutaneous pocket in the anterior abdomen. (C) Georg Thieme Verlag KG. Reproduced from Rodríguez L, Rodriguez P, Gómez B, et al. Long-term results of electrical stimulation of the lower esophageal sphincter for the treatment of gastroesophageal reflux disease. Endoscopy. 20I3;45: 595-604. ${ }^{20}$

Abbreviations: IPG, implantable pulse generator; LES, lower esophageal sphincter.

median (interquartile range [IQR]) scores of $0(0-3)$ vs 23.5 (21-25.3) and $9(6-10)$, respectively $(P<0.01)$. Heartburn and regurgitation severity scores were significantly improved compared to baseline values (Figure 4). Esophageal $\mathrm{pH}$ monitoring showed a significant improvement in esophageal acid exposure compared to baseline (Figure 5) with $71 \%$ demonstrating either normalization or at least a $50 \%$ reduction in esophageal acid exposure. Seventy-six percent of patients reported complete cessation of PPI use. A total of 65 events occurring in 19 subjects were reported, almost all in the first year, as described earlier. No new SAEs were reported, and the additional adverse events were considered not related to device or procedure, with events involving the respiratory system being the most common. As in the first year, there were no reports of new dysphagia or other gastrointestinal complaints.

Fifteen patients completed their 3-year evaluation while on LES stimulation. At 3 years, the improvement in GERDHRQL and acid exposure was still sustained. Median GERDHRQL on electrical stimulation was significantly improved compared to scores both on PPI (9 [IQR: 6-10] vs 1 [IQR: $0-2$ ], $P=0.001$ ) and off PPI (22 [IQR: $21-24]$ vs 1 [IQR: $0-2], P<0.001)$. Median 24-hour distal esophageal acid exposure was significantly reduced from $10.3 \%$ (7.5-11.6) at baseline vs $3 \%$ at 3 years $(1.9-4.5)(P<0.001)$. Seventythree percent $(11 / 15)$ of patients had normalized their distal esophageal acid exposure at 3 years. The remaining four patients had improved their distal esophageal acid exposure 

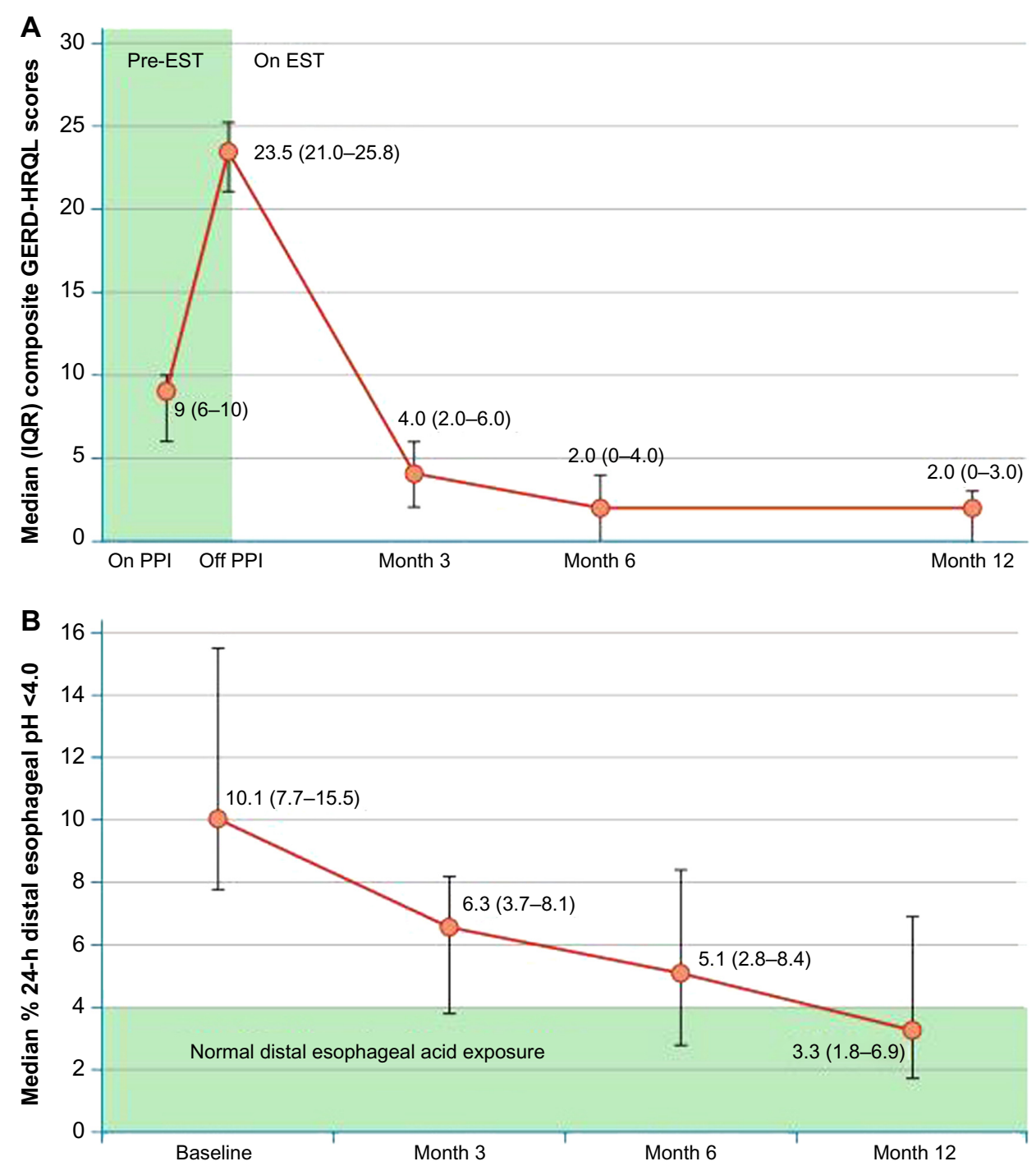

Figure 3 Improvement in the outcomes of GERD.

Notes: (A) Significant improvement in median (IQR) GERD-HRQL composite scores at 6 and 12 months compared with baseline scores (highlighted in green) both on and off proton pump inhibitor (PPI) therapy. (B) Change in median (IQR) distal esophageal $\mathrm{pH}$ on lower esophageal sphincter EST from baseline to 3 months (6 months [ $\mathrm{n}=23$ ] and 12 months [ $n=22$ ]; $P=0.002$ at 3 months vs baseline and $P<0.001$ at 6 and 12 months vs baseline [related-sample Wilcoxon signed-rank test]). The distal esophageal acid exposure had either normalized or showed $>50 \%$ improvement in $77 \%$ of patients at 12 months. Normal value highlighted in green. (C) Georg Thieme Verlag KG. Reproduced from Rodríguez L, Rodriguez P, Gómez B, et al. Long-term results of electrical stimulation of the lower esophageal sphincter for the treatment of gastroesophageal reflux disease. Endoscopy. 2013;45:595-604. ${ }^{20}$

Abbreviations: EST, electrical stimulation therapy; GERD, gastroesophageal reflux disease; GERD-HRQL, GERD Health-Related Quality of Life; IQR, interquartile range.

by $39 \%-48 \%$ from baseline. All but four patients reported cessation of regular PPI use ( $>50 \%$ of days with PPI use). There were no unanticipated device- or stimulation-related adverse events or untoward sensations reported during the 2 - to 3-year follow-up. No dysphagia was reported. ${ }^{22}$

\section{Multicenter study}

Forty-one GERD patients with partial response to PPI were enrolled in a prospective, open-label, uncontrolled, international, multicenter study that was conducted at ten sites in eight countries, and 6-month interim results have been recently published. ${ }^{23}$ Patients were implanted with a system similar to the one used in the single-center study, and stimulation was initiated at $20 \mathrm{~Hz}, 220 \mu \mathrm{s}$, and $5 \mathrm{~mA}$ delivered in 12 sessions, each lasting for 30 minutes. There was a significant improvement in both GERD-HRQL and esophageal acid exposure at the end of 6 months: GERD-HRQL improved from a median of 31.0 (IQR 26.2-36.8) off PPI and 16.5 (IQR 9.0-22.8) on PPI at baseline to 5 (IQR 3-9) at 6-month follow-up $(P<0.0001$ vs on and off PPI). Esophageal acid exposure $(\mathrm{pH}<4.0)$ improved from $10.0 \%$ (IQR 7.5-12.9) to $4.4 \%$ (IQR 2.2-7.2) at 6 months $(P<0.0001)$ (Figures 6 and 7 ). Comparable to the single-center study, there was a significant reduction in daytime and nighttime episodes of 


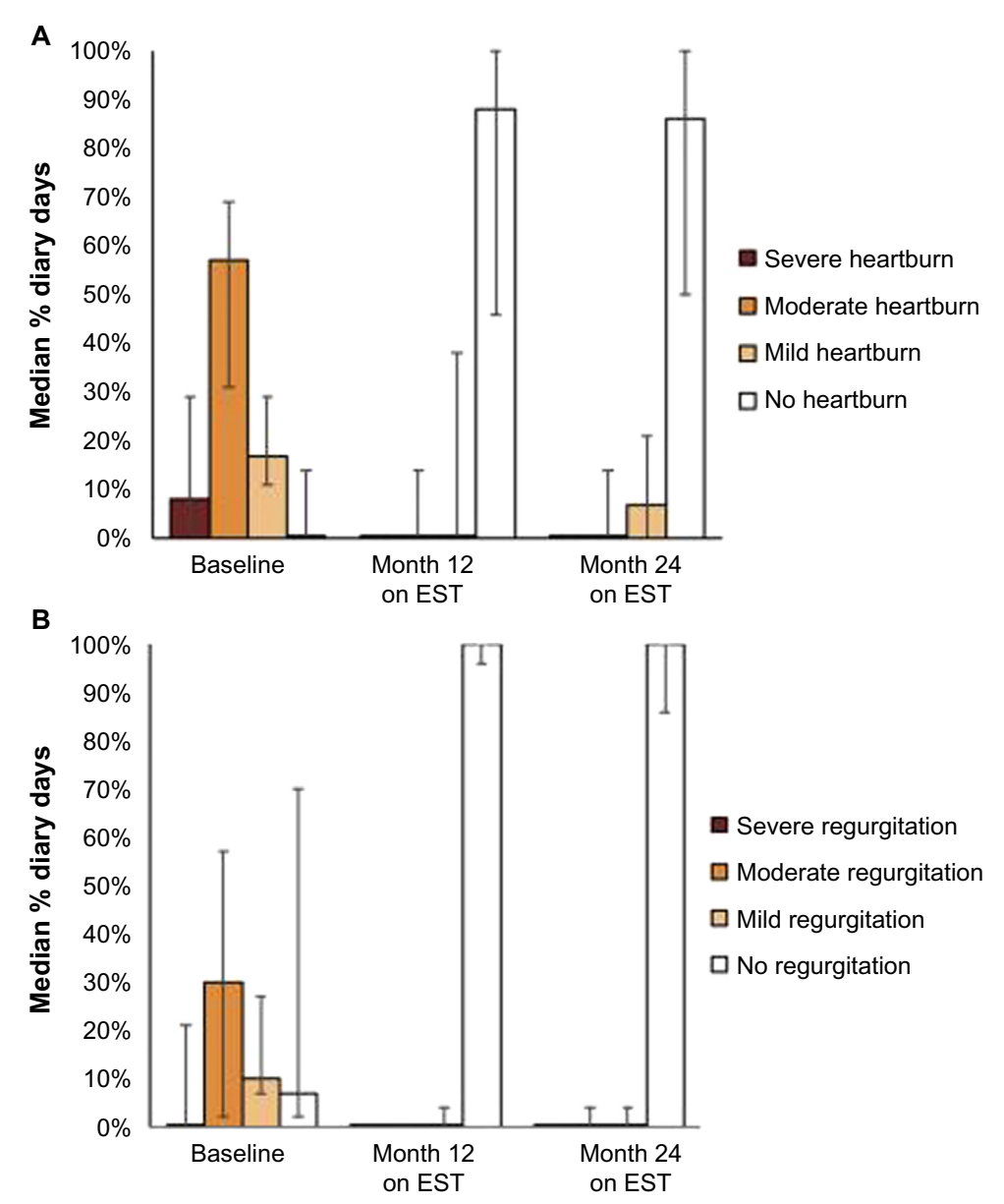

Figure 4 Severity of GERD symptoms obtained from subjects' daily diaries.

Notes: (A) Heartburn symptom severity (median [IQR]; \% diary days). (B) Regurgitation symptom severity (median [IQR]; \% diary days). Reprinted from Surgery; 20I5; 157; Rodríguez L, Rodriguez P, Gómez B, et al. Two-year results of intermittent electrical stimulation for the lower esophageal sphincter treatment of gastroesophageal reflux disease; 556-567; Copyright () 2015 Elsevier Inc. All rights reserved; with permission from Elsevier. ${ }^{21}$

Abbreviations: EST, electrical stimulation therapy; GERD, gastroesophageal reflux disease; IQR, interquartile range.

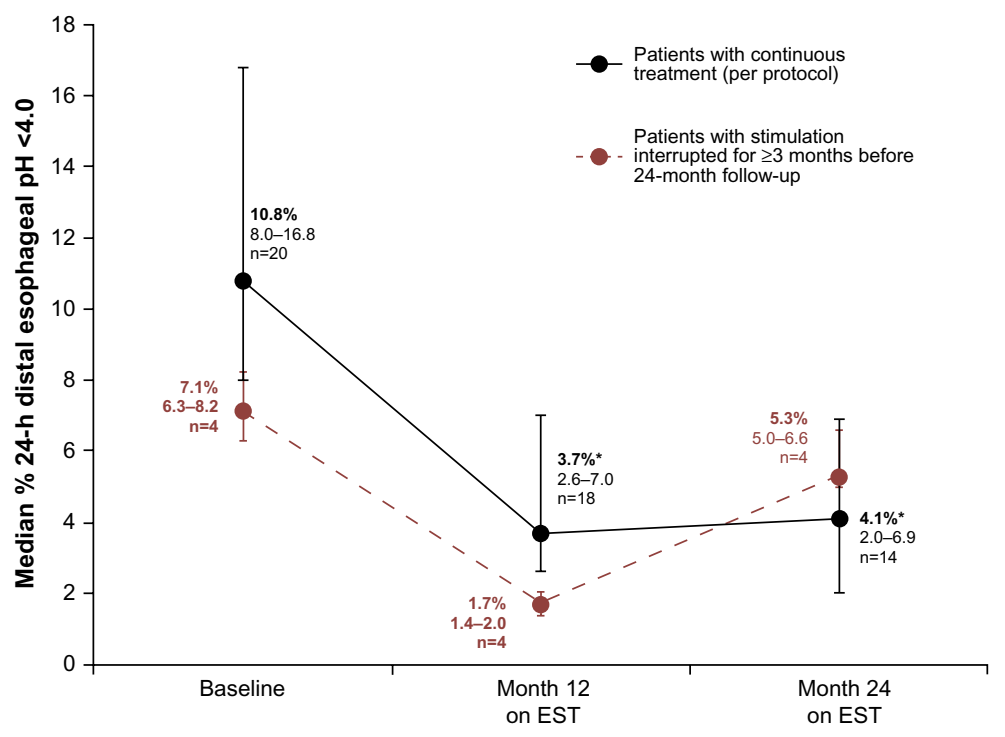

Figure 5 Change in 24-hour distal esophageal pH (median [IQR] \% 24-hour $\mathrm{pH}<4.0$ ) with EST.

Notes: Four patients had therapy interrupted for $\geq 3$ months prior to 24 -month follow-up. $* P<0.00 I$ vs baseline at months 12 and 24 . There was no difference between 12 and 24 months in patients treated per protocol $(P=0.45)$. Reprinted from Surgery; 2015; I57; Rodríguez L, Rodriguez $P$, Gómez B, et al. Two-year results of intermittent electrical stimulation for the lower esophageal sphincter treatment of gastroesophageal reflux disease; 556-567; Copyright (C) 20I5 Elsevier Inc. All rights reserved; with permission from Elsevier. ${ }^{21}$

Abbreviations: EST, electrical stimulation therapy; IQR, interquartile range. 


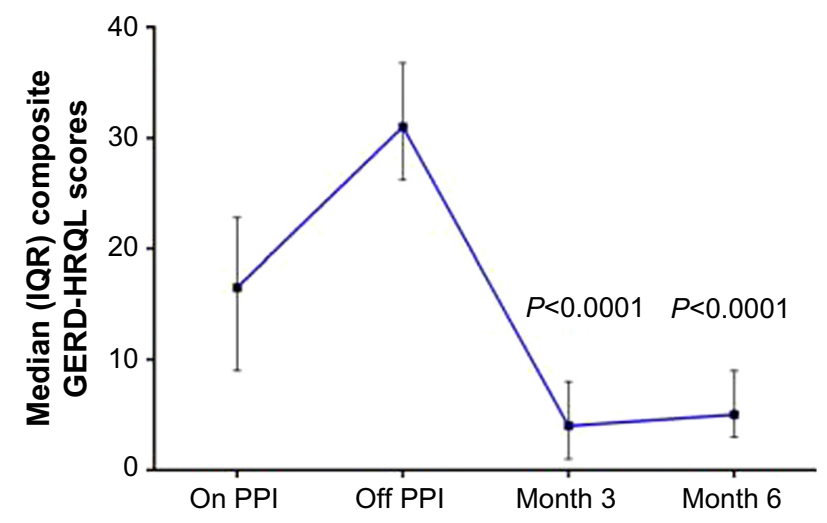

Figure 6 Change in GERD-HRQL composite scores from baseline while on electrical stimulation therapy.

Notes: GERD-HRQL deteriorated after cessation of PPI and improved significantly at 3 and 6 months after start of electrical stimulation therapy, as compared to baseline values while on and off PPI. Data are presented as median (IQR). Reproduced from Kappelle WF, Bredenoord AJ, Conchillo JM, et al. Electrical stimulation therapy of the lower esophageal sphincter for refractory gastro-oesophageal reflux disease interim results of an international multicentre trial. Aliment Pharmacol Ther. 2015;42(5):614-625. (C) 2015 John Wiley \& Sons Ltd. ${ }^{23}$

Abbreviations: GERD-HRQL, GERD Health-Related Quality of Life; IQR, interquartile range; PPI, proton pump inhibitor.

regurgitation. Hiatal hernia was present in 25 of the patients, and hernia repair was left to the discretion of the surgeon in each center. Though numbers were small, esophageal acid exposure was further improved in patients who underwent a hernia repair. In total, 110 AEs were reported in 32 patients, of which three were SAEs. Two were considered procedure or device related. One SAE was a trocar perforation of the small bowel, which occurred during the implant procedure and was successfully laparoscopically repaired. The device was explanted and the patient recovered fully. One asymptomatic

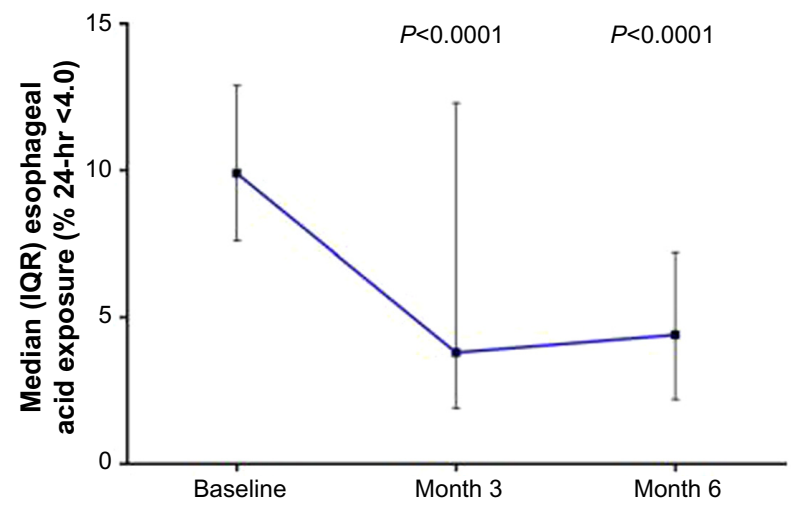

Figure 7 Change in distal esophageal acid exposure while on electrical stimulation therapy.

Notes: Distal esophageal acid exposure at both 3 and 6 months was reduced as compared to baseline. After 6 months, $63 \%$ of patients had either normalized or improved their distal esophageal acid exposure by at least $50 \%$ while on lower esophageal sphincter stimulation. Data are presented as median (IQR). Reproduced from Kappelle WF, Bredenoord AJ, Conchillo JM, et al. Electrical stimulation therapy of the lower esophageal sphincter for refractory gastro-oesophageal reflux disease - interim results of an international multicentre trial. Aliment Pharmacol Ther. 2015;42(5):614-625. (C) 2015 John Wiley \& Sons Ltd. ${ }^{23}$

Abbreviation: IQR, interquartile range. lead erosion was encountered at the 6-month endoscopy in a patient implanted with an investigational, modified lead that was different from the standard lead. The system was explanted and the patient underwent a Toupet fundoplication performed during the same procedure. The third SAE was a case of paroxysmal atrioventricular nodal reentrant tachycardia several months after the start of LES electrical stimulation, in a patient with history of uninvestigated tachycardia that was not disclosed at the time of inclusion. The patient underwent successful therapeutic ablation, and electrical stimulation therapy was resumed without further events. This event was not considered device or therapy related. Of the remaining adverse events, half were not considered device or therapy related, and the other half consisted mostly of postoperative symptoms.

\section{Summary and conclusion}

Electrical stimulation of the LES is a promising intervention for GERD. The safety profile of LES electrical stimulation has been very satisfactory thus far. The therapy significantly improves both heartburn and regurgitation. The simplicity of the intervention should provide for a more uniform postoperative outcome as compared to the more variable outcomes observed with laparoscopic fundoplication. ${ }^{9}$ The ability to adjust and optimize therapy by changing pulse parameters and the number of sessions delivered is of benefit. However, all clinical data thus far are derived from open label trials and commercial registries, and lack data from control groups. Thus, assessment of subjective variables is susceptible to a placebo effect, and a sham-controlled trial is needed. However, a review of several randomized controlled trials of procedures intended to treat GERD demonstrated that the placebo effect of a sham intervention on acid exposure is small or nonexistent. ${ }^{24}$ Thus, the significant improvement in esophageal acid exposure observed in single- and multicenter studies, which was sustained for up to 3 years in the single-center study, strongly suggests an effect that addresses the pathophysiology of GERD. ${ }^{22,23}$ While a larger number of implanted patients and longer follow-up are clearly needed to determine long-term safety, experience with gastric electrical stimulation for the treatment of gastroparesis (which uses implanted gastric electrodes and pulse generator, and a surgical approach and hardware that are comparable to LES electrical stimulation), suggests that such an intervention has a very good safety profile. ${ }^{25}$

The mechanisms of action of LES electrical stimulation are not fully understood, and the stimulation-induced increase in LES pressure that was observed primarily in acute and short-term studies in both animals and humans may be 
only one factor accounting for the beneficial effect of this intervention. Other mechanisms affecting such pathophysiological aspects of GERD such as transient LES relaxation or the acid pocket remain to be elucidated.

Both single- and multicenter studies addressed the need of patients with GERD who were not satisfied with current pharmacologic therapy and who desired an alternative to fundoplication..$^{22,23}$ The selective enrollment criteria excluded patients with significant hiatal hernia, Barrett's metaplasia, esophageal contractile impairment, and severe erosive esophagitis. These selective criteria are comparable to those used in initial studies of alternative interventions for GERD, endoscopic or surgical. Consequently, the applicability of electrical stimulation therapy to the wider population of GERD patients remains to be determined by future studies and further experience. Limited experience obtained thus far in a small number of subjects suggests that patients with impaired esophageal body motor function may be particularly suited to this therapy, given the normal LES residual pressure associated with swallows. Similarly, a beneficial effect was also observed in a few patients who developed GERD after undergoing sleeve gastrectomy for obesity, an evolving problem. ${ }^{26}$ Further experience will determine the place of LES electrical stimulation in the armamentarium of anti-reflux interventions in patients with GERD.

\section{Disclosure}

Professor Edy Soffer owns stocks in Endostim. The authors report no other conflicts of interest in this work.

\section{References}

1. Sandler RS, Everhart JE, Donowitz M, et al. The burden of selected digestive diseases in the United States. Gastroenterology. 2002;122: $1500-1511$.

2. El-Serag HB, Sweet S, Winchester CC, Dent J. Update on the epidemiology of gastro-oesophageal reflux disease: a systematic review. Gut. 2014;63:871-880.

3. Becher A, Al-Serag H. Systematic review: the association between symptomatic response to proton pump inhibitors and health-related quality of life in patients with gastro-oesophageal reflux disease. Aliment Pharmacol Ther. 2011;34:618-627.

4. Joish VN, Donaldson G, Stockdale W, et al. The economic impact of GERD and PUD: examination of direct and indirect costs using a large integrated employer claims database. Curr Med Res Opin. 2005;21: 535-544.

5. Kaltenbach T, Crockett S, Gerson LB. Are lifestyle measures effective in patients with gastroesophageal reflux disease? An evidence-based approach. Arch Intern Med. 2006;166:965-971.

6. El-Serag H, Becher A, Jones R. Systematic review: persistent reflux symptoms on proton pump inhibitor therapy in primary care and community studies. Aliment Pharmacol Ther. 2010;32:720-737.
7. Sifrim D, Zerbib F. Diagnosis and management of patients with reflux symptoms refractory to proton pump inhibitors. Gut. 2012;61: $1340-1354$.

8. Kahrilas PJ, Howden CW, Hughes N. Response of regurgitation to proton pump inhibitor therapy in clinical trials of gastroesophageal reflux disease. Am J Gastroenterol. 2011;106:1419-1425.

9. Vakil N, Shaw M, Kirby R. Clinical effectiveness of laparoscopic fundoplication in a US community. Am J Med. 2003;114:1-5.

10. Fass R, Sifrim D. Management of heartburn not responding to proton pump inhibitors. Gut. 2009;58:295-309.

11. Johnson DA, Oldfield EC 4th. Reported side effects and complications of long-term proton pump inhibitor use: dissecting the evidence. Clin Gastroenterol Hepatol. 2013;11:458-464.

12. Richter JE. Gastroesophageal reflux disease treatment: side effects and complications of fundoplication. Clin Gastroenterol Hepatol. 2013;11:465-471.

13. Wang YR, Dempsey DT, Richter JE. Trends and perioperative outcomes of inpatient antireflux surgery in the United States, 1993-2006. Dis Esophagus. 2011;24:215-223.

14. Kahrilas PJ. Magnetic enhancement of the lower esophageal sphincter. Gastrointest Endosc. 2008;67:295-296.

15. Ellis F, Berne TV, Settevig K. The prevention of experimentally induced reflux by electrical stimulation of the distal esophagus. Am J Surg. 1968;115:482-487.

16. Clarke JO, Jagannath SB, Kalloo AN, Long VR, Beitler DM, Kantsevoy SV. An endoscopically implantable device stimulates the lower esophageal sphincter on demand by remote control: a study using a canine model. Endoscopy. 2007;39:72-76.

17. Sanmiguel CP, Hagiike M, Mintchev MP, et al. Effect of electrical stimulation of the LES on LES pressure in a canine model. Am J Physiol Gastrointest Liver Physiol. 2008;295:389-394.

18. Rodríguez L, Rodríguez P, Neto MG, et al. Short-term electrical stimulation of the lower esophageal sphincter increases sphincter pressure in patients with gastroesophageal reflux disease. Neurogastroenterol Motil. 2012;24:446-450.

19. Banerjee R, Pratap N, Kalpala R, Reddy DN. Effect of electrical stimulation of the lower esophageal sphincter using endoscopically implanted temporary stimulation leads in patients with reflux disease. Surg Endosc. 2014;28:1003-1009.

20. Rodríguez L, Rodriguez P, Gómez B, et al. Long-term results of electrical stimulation of the lower esophageal sphincter for the treatment of gastroesophageal reflux disease. Endoscopy. 2013;45:595-604.

21. Rodríguez L, Rodriguez P, Gómez B, et al. Two-year results of intermittent electrical stimulation for the lower esophageal sphincter treatment of gastroesophageal reflux disease. Surgery. 2015;157:556-567.

22. Rodríguez L, Rodriguez P, Gómez B, Netto MG, Crowell MD, Soffer E. Electrical stimulation therapy of the lower esophageal sphincter is successful in treating GERD: long-term 3-year results. Surg Endosc. Epub 2015 Oct 20.

23. Kappelle WF, Bredenoord AJ, Conchillo JM, et al. Electrical stimulation therapy of the lower esophageal sphincter for refractory gastrooesophageal reflux disease - interim results of an international multicentre trial. Aliment Pharmacol Ther. 2015;42(5):614-625.

24. Rothstein RI. Endoscopic therapy of gastroesophageal reflux disease: outcomes of the randomized-controlled trials done to date. J Clin Gastroenterol. 2008;42:594-602.

25. McCallum RW, Lin Z, Forester J, Roeser Kl, Hou Q, Sarosiek I. Gastric electrical stimulation improves outcomes of patients with gastroparesis for up to 10 years. Clin Gastroenterol Hepatol. 2011;9:314-319. e1.

26. DuPree CE, Blair K, Steele SR, Martin MJ. Laparoscopic sleeve gastrectomy in patients with preexisting gastroesophageal reflux disease: a national analysis. JAMA Surg. 2014;149(4):328-334. 


\section{Publish your work in this journal}

Clinical and Experimental Gastroenterology is an international, peerreviewed, open access journal, publishing all aspects of gastroenterology in the clinic and laboratory, including: Pathology, pathophysiology of gastrointestinal disease; Investigation and treatment of gastointestinal disease; Pharmacology of drugs used in the alimentary tract;
Immunology/genetics/genomics related to gastrointestinal disease. This journal is indexed on CAS. The manuscript management system is completely online and includes a very quick and fair peer-review system. Visit http://www.dovepress.com/testimonials.php to read real quotes from published authors.

Submit your manuscript here: http://www.dovepress.com/clinical-and-experimental-gastroenterology-journal 